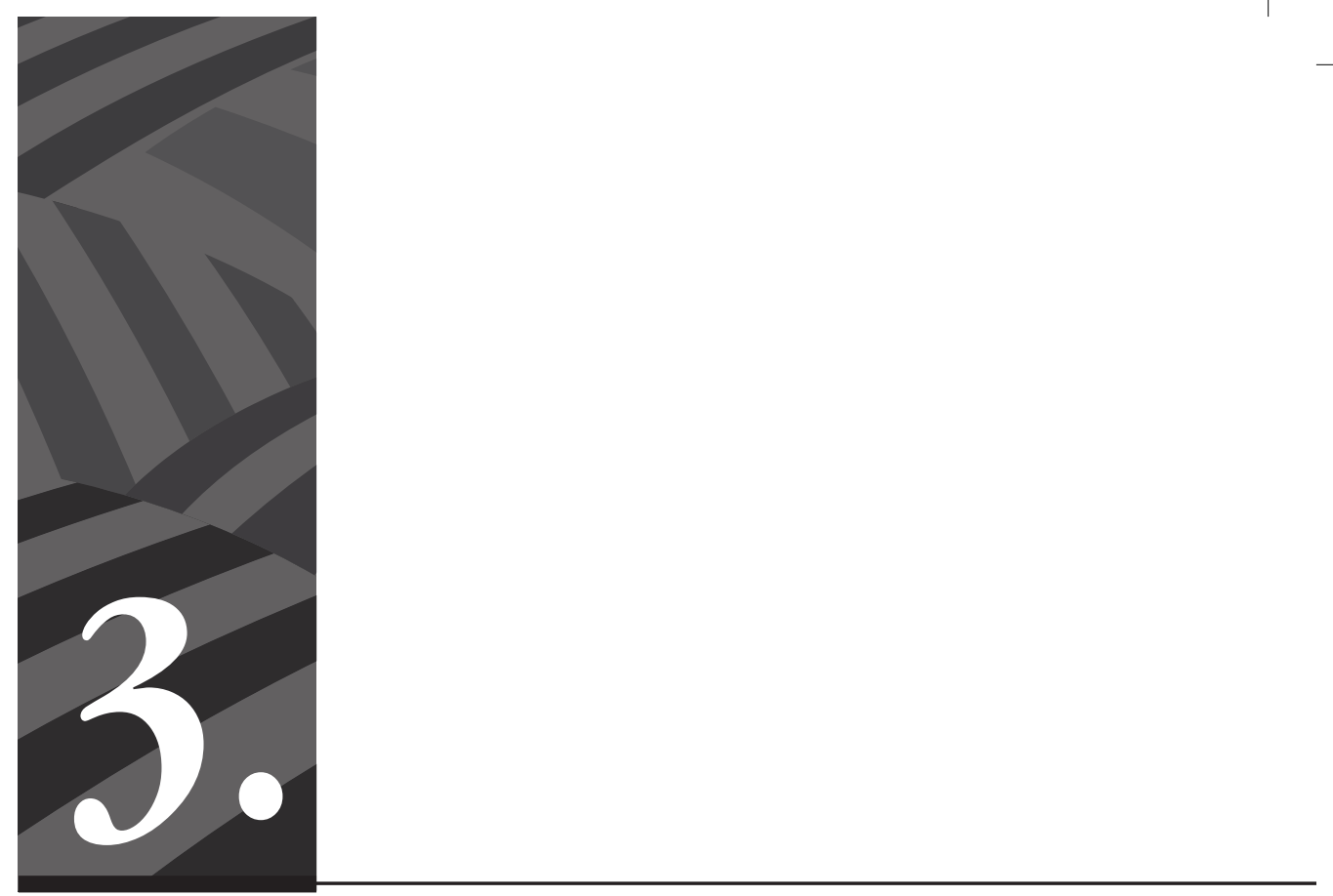

Reivindicaciones interseccionales.

El caso de la Red

Nacional de Mujeres

Afrodescendientes Kambirí 


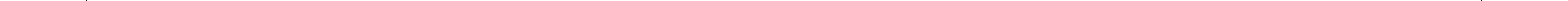




\title{
Reivindicaciones interseccionales. El caso de la Red Nacional de Mujeres Afrodescendientes Kambirí
}

\author{
Por Diana Carolina Angulo Ramírez
}

Resumen: La organización Red Nacional de Mujeres Afrocolombianas Kambirí ha emprendido procesos de acción colectiva desde la interseccionalidad y sus demandas particulares. Avanzan en su proceso de empoderamiento, a pesar de las discriminaciones interseccionales e intolerancia, incluso dentro del feminismo, frente a los procesos organizativos de mujeres y lideresas defensoras de derechos humanos. La interseccionalidad permite analizar y entender las situaciones de discriminación y las opresiones a nivel estructural que viven en la sociedad a través de sus instituciones. Se concluye que el activismo desde el feminismo y el reconocimiento de los derechos humanos como discurso y herramienta jurídica vinculante son los instrumentos fundamentales para visibilizar las múltiples discriminaciones y atacar las situaciones de injusticia que surgen en torno a las mujeres afrodescendientes.

Palabras clave: interseccionalidad, sororidad, feminismo, empoderamiento, black feminism.

\section{Intersectional claims. The case of the National Network of Afro-descendant Women Kambirí}

Abstract: The National Network of Afro-Colombian Women Kambirí organization has undertaken processes of collective action based on intersectionality and its particular demands, advancing in its process of empowerment despite intersectional discrimination and intolerance, even within feminism, facing organizational processes of women and human rights defender leaders, intersectionality allows to analyze and understand the situations of discrimination and oppression at the structural level that live in society through their institutions, It's concluded that activism

* El artículo hace parte de mi trabajo de investigación, titulado Acción colectiva e interseccionalidad en la red nacional de mujeres afrocolombianas Kambirí, presentado a la Universidad del Rosario para obtener el título de magíster en Estudios Políticos e Internacionales

** Abogada de la Universidad Santo Tomás, especialista en Derecho Administrativo de la Universidad del Rosario y magíster en Estudios Políticos e Internacionales de la misma Universidad. diana.angulo@urosario.edu.co 
from Feminism and the recognition of Human Rights as a discourse and linking legal tool are the fundamental instruments to make visible the multiple discriminations and attack the situations of injustice that are exercised against afrodescendant women.

Keywords: Intersectionality, sorority, feminism, empowerment, black feminism.

Cómo citar este artículo: Angulo Ramírez, Diana Carolina (2018). Reivindicaciones interseccionales. El caso de la Red Nacional de Mujeres Afrodescendientes Kambirí. Revista Controversia, 211, 95-135.

Fecha de recepción: 27 de junio de 2018

Fecha de aprobación: 25 de septiembre de 2018

\section{Contextualización}

$\mathrm{E}$ 1 informe de Colombia para la Comisión Interamericana de Derechos Humanos (2014) señala que las mujeres afrocolombianas sufren varias discriminaciones por el hecho de ser mujeres, afrocolombianas y desplazadas, lo que las pone en una situación de labilidad preocupante ${ }^{1}$.

En ese sentido, son interesantes los planteamientos de Audré Lorde (2002) sobre el enfoque de interseccionalidad ${ }^{2}$, cuando señala que los grupos marginados suelen identificar una sola forma de exclusión, que

1 Así se encuentra señalado en el Informe País 2014, de la Comisión Interamericana de Derechos Humanos: "En el pasado, la Comisión ha podido constatar que, en el caso de las mujeres afrocolombianas, su condición de mujeres añadía otro factor de discriminación y vulnerabilidad, las exponía a mayores abusos por parte de los actores del conflicto, así como también, que la situación de las mujeres afrocolombianas que habitaban en la zona de la Costa pacífica era especialmente precaria y preocupante. La cidh también señaló que el desplazamiento conllevaba que las mujeres afrocolombianas sufrieran varias formas de discriminación que se sumaban a las padecidas por el hecho de ser mujeres, por ser afrocolombianas y por estar desplazadas".

2 Interseccionalidad: término introducido por Kimberlé Crenshaw (1989). Las personas individuales están relacionadas con "identidades, privilegios y formas de opresión étnicas, funcionales, sexuales y de género interconectadas que no pueden abordarse de manera individual”. 
identifican como la única causa de la opresión, y olvidan otras opresiones impuestas por la sociedad. La autora también hace una fuerte crítica al feminismo estadounidense, que plantea como única forma de opresión su condición de género y obvia categorías como la raza, la clase, la orientación sexual y la edad, discriminaciones de las cuales son víctimas las mujeres afrodescendientes, para este caso, las mujeres afrocolombianas.

Al hablar de feminismo, reconozco la diversidad misma del movimiento y las tensiones que surgen en su interior. Por eso, en adelante, usaré la palabra feminismos para expresar que no es solo uno, sino que existen varias perspectivas o construcciones de los feminismos que han surgido en momentos distintos de la historia.

Patricia Hill Collins (2012) va más allá de proponer la interseccionalidad como un enfoque para analizar la situación de las mujeres afrodescendientes y de otros grupos oprimidos. Sugiere que el feminismo negro es una de las formas de liberarse de las opresiones interseccionales de raza, género, sexualidad y clase, pues su objetivo es empoderar mediante la eliminación de las opresiones interseccionales a las mujeres de raíces africanas que, en distintas partes del mundo, han sido sometidas a injusticias.

La interseccionalidad planteada por Audré Lorde, y citada por Ángela Santamaría ${ }^{3}$ (2012), expone que, estos estudios:

[...] permiten pensar diferentes formas de dominación, no de forma paralela, sino como sistemas imbricados los unos con los otros. [...] las diferencias no son, en consecuencia, alineadas de forma que no mantengan ninguna relación: estas se insertan en un contexto hegemónico. De esta

3 Es pertinente señalar que la especialidad de Santamaría es el trabajo con mujeres indígenas, pero se ha apoyado en los estudios del black feminism para entender las realidades y los procesos de las mujeres que estudia. Este es un claro ejemplo de que esta teoría permite entender otras realidades de otros grupos oprimidos, no solo de las mujeres afrodescendientes. 
forma, las estructuras de dominación son desarrolladas y consolidadas en la relación con lo que es considerado como la norma y con lo que aparece como diferente (p. 257).

Asimismo, es importante "el cruce entre las categorías género, raza y clase desde el movimiento del black feminism", que señala Santamaría al referirse a lo planteado por Patricia Hill Collins así:

La autora afirma que es necesario teorizar desde las ideas y las experiencias de mujeres negras ordinarias para comprender la visión de sí mismas, de la sociedad y de la comunidad. Solo a través de los estudios feministas postcoloniales que deconstruyan las categorías y prácticas del racismo, el sexismo y la opresión de clase, será posible la liberación de las mujeres negras y de otras como las indígenas (pp. 257-258).

La problemática de las mujeres afrocolombianas es histórica, dramática y dolorosa. En primer lugar, está el secuestro ejecutado en África por los colonizadores para conducirlas hasta América, hecho que afectó tanto a hombres como a mujeres y que inició el proceso de esclavitud y la diáspora africana. Esto tuvo y sigue teniendo un impacto en la vida de las mujeres afrocolombianas que, con escasas excepciones, han vivido a la zaga del desarrollo y de las oportunidades laborales y educativas, entre otras razones, por falta de inversión del Estado colombiano en los territorios que tradicionalmente han habitado. Adicionalmente, como lo señala el informe del PCN (2012), "derrotar la invisibilidad es un reto para las mujeres afrodescendientes en Colombia". Las mujeres afrocolombianas han vivido las consecuencias del conflicto armado, que trajo consigo el desplazamiento forzado, el abandono sistemático de sus tierras, la militarización de sus territorios y la violencia sistemática contra sus cuerpos, pues fueron víctimas de abuso sexual, simbólica y psicológicamente, por parte de los actores armados legales e ilegales.

Aunado a lo anterior, ellas han sido víctimas de la violencia de género, la discriminación racial, la falta de acceso a la educación y a oportunidades laborales distintas de las domésticas, y sus niveles de pobreza superan aquellos de las mujeres mestizas. Así lo demuestra el último 
informe de la situación de derechos humanos de las mujeres afrocolombianas $2013^{4}$, presentado por la Mesa Nacional de Organizaciones Afrocolombianas 5 , que señala:

En la actualidad las mujeres negras-afrocolombianas sufren una brecha de desigualdad amplia entre las condiciones de pobreza que viven y las que afrontan las mujeres no étnicas. Las mujeres afrocolombianas en regiones como el Pacífico, Valle, Antioquia y Bogotá superan los porcentajes de pobreza en comparación con las mujeres no étnicas, y en el total nacional se encuentran muy por encima del resto de mujeres del país (Viáfara, 2013, p. 17).

Por otra parte, el racismo que impera en la sociedad colombiana ha sido heredado de la visión miope de los roles que debían cumplir las mujeres afrodescendientes durante la colonia, que se veían reflejados en las relaciones de poder, de dominación y explotación que ejercía el colono sobre su cuerpo. A través de los siglos, ha sido un reto superar las condiciones de precariedad en las que aún se encuentra un alto porcentaje de las mujeres afrocolombianas, no solo, como ya se mencionó, por falta de oportunidades laborales, educativas, de acceso a información y nuevas tecnologías, sino también por la falta de inversión social del Estado en términos de educación, salud, servicios públicos e infraestructura, entre otros.

Esta situación ha afectado a las mujeres afrocolombianas de varias formas, particularmente, en sus cuerpos, como lo señala Tomasa Medrano ${ }^{6}$, cuando dice que en Colombia "los cuerpos de las mujeres afro han sido leídos con fines sexuales”. Dada su fisionomía, en algunas

4 Ese informe se hizo con el apoyo de Agencia Española de Cooperación Internacional para el Desarrollo (Aecid), el Fondo para la Sociedad Civil Colombiana (FOS), la Embajada de Noruega y la Embajada de Suecia.

5 Esta mesa está conformada por Afrodes, la Conferencia Nacional de Organizaciones Afrocolombianas y el Movimiento Nacional Cimarrón.

6 Tomasa Medrano es mujer afrocolombiana y una de las fundadoras de la Red Nacional de Mujeres Kambirí, licenciada en Geografía e Historia de la Universidad de Antioquía, pensionada y actualmente dedicada a la docencia en la Institución Educativa Municipal de Turbo, Antioquía. 
ocasiones, los hombres mestizos o "blancos" las ven como objeto sexual, pero no dignas de ser presentadas a sus padres o a su círculo social (Fanon, 1973). Esta situación obedece al lastre histórico de la esclavitud y del racismo que han impuesto en la sociedad colombiana una visión eurocéntrica de belleza y de aceptación de la misma, que consolida los estereotipos por el modelo de dominación colonial, en el que la mujer afrocolombiana era esclavizada y sometida a todo tipo de vejaciones, de manera oculta y soterrada por parte del esclavizador ${ }^{7}$ (Viveros, 2000).

En ese mismo sentido, Rita Laura Segato (2011) describe la situación de las mujeres afrodescendientes e indígenas durante la colonización, cuando señala que esta trajo consigo una mirada pornográfica de la mujer, que redujo su sexualidad, para convertir su cuerpo en un objeto (pp. 17-18). Así, los procesos de esclavización y dominación incluían todo tipo de violencias físicas, psicológicas y simbólicas sobre los hombres y mujeres secuestrados y traídos desde el continente africano.

Actualmente, las mujeres afrocolombianas siguen siendo víctimas de lo que Bourdieu (2007) llama la violencia simbólica, definida por el autor como "aquella que se ejerce sobre una persona a través de los medios de comunicación, de la imposición de un cierto estilo de vida, de una forma particular de hablar, de comportarse” (p. 5).

Estas circunstancias han sido heredadas del colonialismo y, a pesar de no ser hoy en día una política de Estado, están arraigadas en la socie-

7 En relación con la problemática que viven las mujeres afrocolombianas, el informe de la situación de los DD. HH. de las mujeres afrocolombianas, realizado por la Mesa Nacional de Organizaciones Afrocolombianas, es diciente: "No se puede comprender la gravedad de la situación de las mujeres negras afrocolombianas sin consultar la historia, la construcción colectiva del concepto de territorialidad producido por las comunidades negras-afrocolombianas, la imposición de la estética eurocéntrica como determinante de la movilidad social ascendente, las epistemologías que se sostienen en la academia y que reproducen una conciencia colectiva racista, sexista y capitalista, y los impactos del conflicto social, político y armado colombiano, que perpetúa la consigna de exterminio que han tenido que padecer los pueblos ubicados en la parte inferior de la clasificación racial de la sociedad". 
dad en la manera de relacionarse con otros, en las subjetividades, en las prácticas culturales, en las formas de pensar y expresarse, y son afianzadas por los medios de comunicación (de Sousa, 2010). No obstante, estas mismas son las que motivan que la mujer afrocolombiana, a través de diversos movimientos sociales, como la Conferencia Nacional de Organizaciones Afrocolombianas (CNOA), la Ruta Pacífica de las Mujeres, el Proceso de Comunidades Negras (PCN), en protesta por su situación de exclusión, se encuentre en el camino de reivindicar su rol como mujer dentro de una sociedad excluyente y machista.

En este contexto, surge la Red Nacional de Mujeres Afrocolombianas Kambirí, organización que empezó a construirse desde el año 1990, mediante la conformación de una Asociación de Mujeres Afrocolombianas (Red Nacional de Mujeres Afrocolombianas Kambirí, 2014). En sus inicios, las mujeres de la Red Nacional de Mujeres Afrocolombianas integraron el movimiento Cimarrón ${ }^{8}$, organización que fue su escuela de liderazgo y de participación política, como lo señala Tomasa Medrano, actual representante legal de la Red: "El movimiento Cimarrón fue nuestra escuela de liderazgo; allí tomamos conciencia étnica y de género" .

Sin embargo, era evidente que dentro de esta organización no existía un interés por los temas concernientes a las mujeres afrocolombianas: parecía un movimiento liderado por hombres. Por esa razón, a mediados del año 2000, varias mujeres miembros coincidieron en la necesidad de crear una red de mujeres afrocolombianas que se reflejara su problemática.

8 El Movimiento Cimarrón "fue fundado en Buenaventura, el 15 de diciembre de 1982, por el Círculo de Estudios de la Problemática de la Comunidades Afrocolombianas (Soweto). El Circulo (Soweto) había surgido desde 1976 en Pereira, Risaralda, y lo integraban estudiantes negros procedentes de diversas regiones del país". El nombre Cimarrón proviene de la época colonial, cuando los pueblos africanos, traídos contra su voluntad a América, lucharon en busca de su libertad. Se llamaba cimarrones a las personas esclavizadas que huyeron a la selva para recuperar su libertad y sociedades libres de esclavitud que se denominaron palenques. Para mayor información: http://movimientocimarron.org/quienes-somos/.

9 Notas de campo. Reunión en la sede de Oxfam en Bogotá con Tomasa Medrano, el día 24 de septiembre de 2014. 
Nació así la Red de Mujeres Afrocolombianas Kambirí, como una Organización No Gubernamental (ONG), con su propia organización administrativa, con sede en la ciudad de Medellín y coordinaciones regionales en los departamentos de Tolima, Atlántico, Chocó, Antioquia, Valle del Cauca, Putumayo y Bogotá, D. C. En la actualidad, esta cuenta con cobertura en dieciocho departamentos de Colombia: Antioquia, Atlántico, Arauca, Bolívar, Caldas, Caquetá Cauca, Chocó, Cesar, Córdoba, Cundinamarca, Guaviare, Nariño, Risaralda, San Andrés, Sucre, Tolima y Valle del Cauca, como expone la figura 1, cuyas zonas verdes indican la presencia a nivel departamental y las zonas naranjas la presencia a nivel municipal.

Desde sus inicios, las integrantes de la RNMAK se han preocupado por los temas educativos y de género, los cuales quieren posicionar a partir de la familia y la escuela, mediante la implementación de la cátedra afrocolombiana, el empoderamiento de las niñas, adolescentes y jóvenes desde la aceptación de sus características étnicas, entre otros propósitos. Este trabajo se practica en las instituciones educativas donde se desempeñan como docentes y donde impulsan la ampliación de los créditos educativos condonables para comunidades afrocolombianas con el Instituto Colombiano de Crédito Educativo y Estudios Técnicos en el Exterior (Icetex), ejercen campañas de alfabetización a mujeres afrocolombianas y gestionan convenios con el Servicio Nacional de Aprendizaje (SENA) y con universidades públicas en los distintos departamentos donde la RNMAK tiene sede, para promover el ingreso a estudiantes afrocolombianas(os) con descuentos en el valor de las matrículas ${ }^{10}$.

10 La RNMAK lleva a cabo planes de acción cada cuatro años, en los que desarrolla líneas estratégicas y acciones como hoja de ruta para el cumplimiento de sus metas. Las acciones enunciadas se encuentran en la línea estratégica de educación del plan estratégico 2003-2005 de la Red. 
Reivindicaciones interseccionales. El caso de la Red Nacional de Mujeres Afrodescendientes Kambirí

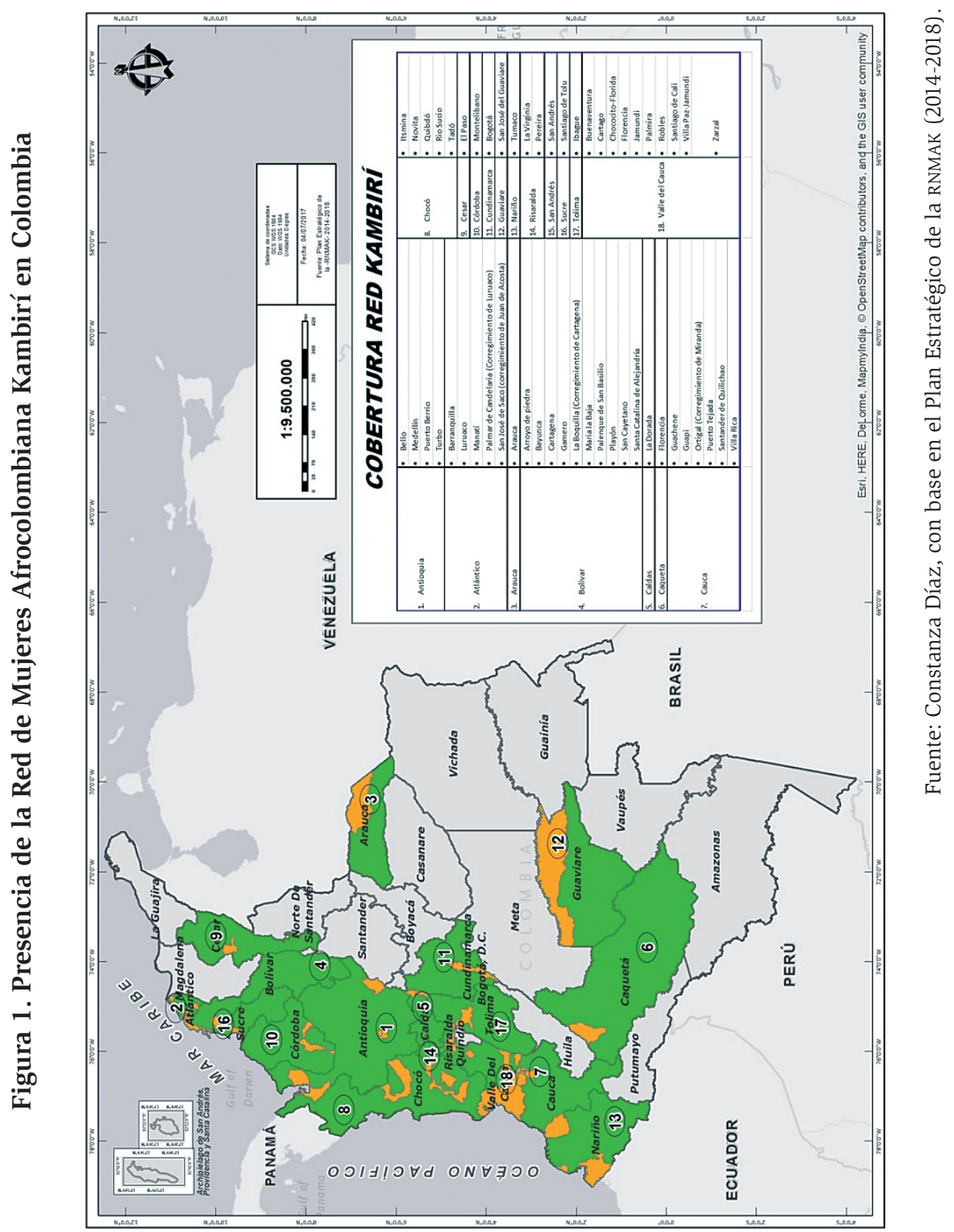


La RNMAK fortalece grupos juveniles desde el aprendizaje de la tradición afrocolombiana, representada en el baile, el teatro y la tradición culinaria, con el fin de alcanzar el denominado "relevo generacional" Uno de los principales temas en los que trabaja la RNMAK es el empoderamiento de las mujeres, a fin de que puedan ocupar los espacios políticos de toma de decisiones. Así lo señalan De la Torre et al., en su libro Empoderamiento y participación política de las mujeres negras, afrodescendientes y palenqueras en Colombia ${ }^{12}$ : “[...] el sueño de la Red Kambirí es ver a las mujeres afrocolombianas posicionadas en los distintos espacios de decisión en el país, incorporando vivencias y costumbres a la construcción de una sociedad más próspera y equitativa para todos" (p. 87).

A su vez, cada coordinación regional prioriza diversos temas, de acuerdo con las necesidades que consideran prioritarias las mujeres afrocolombianas que pertenecen a las RNMAK y que, por sus liderazgos e historias de vida, reafirman en cada territorio, por ejemplo, la etnoeducación, las nuevas ciudadanías y liderazgos y el trabajo sobre mujeres populares y políticas. La visión de las mujeres afrocolombianas de la Red es:

Ser la Red de Mujeres Afrocolombianas líder a nivel nacional e internacional, con fundamento sólido a partir de las bases, con capacidad de incidencia en los espacios de toma de decisiones en lo étnico, cultural, político y de género, que permita a las mujeres y al conjunto de la población afrocolombiana el disfrute de una vida digna y el ejercicio pleno de sus derechos ${ }^{13}$.

11 Notas de campo. Reunión en la sede de Oxfam en Bogotá con Tomasa Medrano, el día 24 de septiembre de 2014.

12 Jenny de la Torre, Candelaria Sepúlveda, Claudia Marín y Narda Berardinelli, integrantes de la RNMAK, escribieron el libro Empoderamiento y participación política de las mujeres negras, afrodescendientes y palenqueras en Colombia, bajo la dirección de la investigadora ecuatoriana María Arboleda, en el marco de un Convenio con Oxfam Intermon, ONG española de cooperación para el desarrollo, asociada a Oxfam Internacional. El libro indaga y visibiliza los procesos de empoderamiento político y participación de mujeres afrodescendientes de Cartagena, Medellín y Quibdó con un enfoque feminista.

13 Tomado del Plan estratégico de la RNMAK 2014-2018. 
En ese sentido, ellas ratifican que han sido víctimas de múltiples discriminaciones vinculadas al género, la clase y a su condición étnica, y, por estas razones, ameritan una agenda diferente dentro de los temas de organizaciones de mujeres. La lucha de las mujeres, en general, ha supuesto una universalización en la que todas las mujeres tienen los mismos intereses y necesidades y sufren las mismas exclusiones; sin embargo, se ha demostrado que las realidades de las mujeres afrodescendientes son diferentes. Como señala la feminista brasileña Sueli Carneiro, citada por Ochy Curiel (2009):

Cuando hablamos del mito de la fragilidad femenina que justificó históricamente la protección paternalista de los hombres sobre las mujeres, ¿de qué mujeres se está hablando? Nosotras - las mujeres negras - formamos parte de un contingente de mujeres, probablemente mayoritario, que nunca reconocieron en sí mismas este mito, porque nunca fueron tratadas como frágiles. Somos parte de un contingente de mujeres que trabajaron durante siglos como esclavas labrando la tierra o en las calles como vendedoras o prostitutas. Mujeres que no entendían nada cuando las feministas decían que las mujeres debían ganar las calles y trabajar. Somos parte de un contingente de mujeres con identidad de objeto. Ayer, al servicio de frágiles señoritas y de nobles señores tarados. Hoy, empleadas domésticas de las mujeres liberadas (p. 6).

Estas particularidades hacen que, incluso dentro de los feminismos, las mujeres afrodescendientes sientan el racismo y la falta de observación de otras mujeres sobre sus luchas particulares. Por eso, es importante señalar que existen diferencias entre los grupos de mujeres y que, a veces, incluso la amplia categoría de mujer implica solo la mirada de la mujer occidental, blanca y burguesa (Segato, 2003). Como lo indica Tomasa, "una mujer educada de la ciudad no vive la misma realidad que una mujer del campo; la mujer de ciudad prende su estufa y cocina, la mujer del campo cocina con leña y lava la ropa en el río"14.

14 Notas de campo. Reunión en la sede de Oxfam en Bogotá con Tomasa Medrano, el día 24 de septiembre de 2014. 
Este relato de Tomasa (mujer afro), su sentir, su experiencia y su trasegar por la vida, evidencian la búsqueda del reconocimiento de la diferencia de las mujeres afrodescendientes en relación con otros grupos de mujeres, que muchas veces no se ve reflejada en la categoría género, por ser demasiado abstracta. Además, desde la academia, dicha categoría se usó para referirse solo a las mujeres blancas, de clase media, lo cual excluía a las mujeres mestizas, afrocolombianas e indígenas $(\mathrm{Cu}-$ riel, 2009, p. 4). Por esta razón, las mujeres que hacen parte de la Red son mujeres que están "buscando espacios equitativos de participación y desarrollo étnico integral” (Red Nacional de Mujeres Afrocolombianas Kambirí, 2014).

En la RNMAK existe una multiplicidad de formas de ser mujeres afrodescendientes y de reconocerse como tales. Algunas de las mujeres entrevistadas, como Tomasa o Deyanira, usan el término mujer afrodescendiente para referirse a ellas mismas; no obstante, observé que no a todas las mujeres afrodescendientes les gusta está denominación. Recuerdo que, en una reunión a la que asistí con Tomasa Medrano, Deyanira y Zulia Mena Valdés, viceministra de Cultura, el 22 de junio de $2016^{15}$, Zulia expresó sobre este tema que a ella le gustaba reconocerse como mujer negra, porque le demostraba a otros que la palabra "negra", que en otra época había tenido un tinte peyorativo, ya no la ofendía y que implicaba para ella haber superado los efectos de la discriminación racial ${ }^{16}$.

En razón a esto, uso el término afrodescendiente como concepción política, que hace referencia a las personas con ascendencia en el continente africano, que se reconocen como un grupo étnico, como un pueblo, y que surge de la autoidentificación de las comunidades negras

15 Es preciso aclarar que, aunque Zulia Mena no hace parte de la RNMAK, sus percepciones como mujer afrodescendiente son importantes para los efectos de mi trabajo de investigación.

16 Notas de campo. Reunión con Tomasa Medrano, Deyanira Valdés y Zulia Mena en el Ministerio de Cultura el día 22 de junio de 2016. 
a partir de la declaración de Durban, dada en la Conferencia Mundial contra el Racismo, celebrada en el año 2001 (de la Torre, et al., 2014). Sin embargo, durante la investigación, las mujeres entrevistadas de la RNMAK utilizaron también el término "negra” para autoidentificarse; así que, a lo largo del artículo, hago uso de los dos términos y aclaro que estos no son sinónimos.

En el presente artículo uso categorías de análisis como interseccionalidad, acción colectiva y sororidad, esta última entendida como ese vínculo, nexo o unión, que las ayuda a salir adelante en situaciones que ellas consideran injustas como la opresión, la violencia, la pobreza, la desigualdad por su género y su etnia. Todo esto las motiva a oponerse a dichas situaciones, a través de su organización, dado que estas categorías aportan elementos que permiten analizar las diversas problemáticas que enfrentan las mujeres afrocolombianas desde los puntos de vista social, cultural, económico, y que las llevan a trabajar en pro de sus derechos y a organizarse como una red. En consecuencia, la investigación que soporta este escrito ha requerido una mirada interdisciplinaria, es decir que, para comprender y responder a esta pregunta, me he apoyado en diversas disciplinas: la ciencia política, las relaciones internacionales, la sociología, la antropología y los estudios de género.

Las problemáticas de las mujeres afrodescendientes que pertenecen a la RNMAK y su forma de organización motivaron que me preguntara por la forma en que emprenden la acción colectiva y la reivindicación de sus derechos, a partir de su condición de género y de etnia como criterios de interseccionalidad, con base en sus propias necesidades y vivencias, distintas de la visión de otras mujeres. Esto implica un ejercicio en lo público, en espacios de toma de decisiones, como también en cargos y posiciones que eran exclusivos de los hombres, dado que las mujeres estaban circunscritas al espacio privado (Flórez, 2004).

Debido a estas problemáticas padecidas por las mujeres negras de la RNMAK —exclusión social, racismo, desplazamiento, confinamiento en 
zonas rurales acechadas por actores armados ilegales en el marco del conflicto armado, pobreza en zonas rurales y falta de oportunidades-, ellas encuentran en la defensa de los derechos humanos y en el feminismo como movimiento social una forma válida de emprender su lucha como mujeres afrocolombianas, pues pretenden la defensa de los derechos de las mujeres y su posicionamiento en espacios que antes eran exclusivos de los hombres.

Es importante mencionar que, el feminismo como teoría académica y como activismo no ha sido incluyente con todas las mujeres, pues aun en sus comienzos fue un movimiento de mujeres blancas burguesas, que luchaban por sus propios intereses de clase (Segato, 2003); como lo señala Francesca Gargallo (2014):

El feminismo blanco y blanquizado que hoy ha logrado espacios de institucionalización significativos no ha escuchado sino las demandas de las mujeres que viven y se quieren liberar dentro de un sistema sexo género binario y excluyente que organiza de igual forma sus saberes y su economía de mercado. Por lo tanto, cuando se dirige a mujeres de otros pueblos, las pretende educar según los parámetros normativos del propio sistema, sin escuchar sus demandas, sin conocer su historia de lucha, sin reconocer validez a sus ideas (p. 11).

La comprensión de las exclusiones presentes en los diversos feminismos acarrea una idea de por qué surgen los feminismos descoloniales - como el indígena o el black feminism - y por qué la lucha y el activismo de las mujeres negras es distinto y merece ser estudiado y analizado de manera diferencial. Es así como lo hace la RNMAK, que busca posicionarse dentro de la agenda política de las demandas de las mujeres negras, basadas en las luchas históricas de sus pueblos por sus derechos, como lo señalaron las mujeres de la Red en la IV Asamblea Nacional: 
Exigimos condiciones dignas de vida, posibilidades laborales para una población que se resiste a la indiferencia estatal. Reclamamos nuestros derechos como lo hicieron en su momento los ancestros africanos con respeto sabiduría y sentido de libertad ${ }^{17}$.

A continuación, expongo cómo surge el black feminism norteamericano y el concepto de interseccionalidad, para conectar con el análisis de: i) los principales hitos en Colombia que cambian los paradigmas del feminismo blanco predominante y gestan los movimientos de mujeres negras, que disienten de las posturas tradicionales de los feminismos, y ii) cómo desde la RNMAK plantean en la agenda pública como estandarte de su organización la diversidad de las mujeres afrocolombianas, sus historias y contextos, y proponen nuevos elementos de análisis de las opresiones interseccionales que sufren, como las relacionadas con la etnia, género y la clase.

\section{Recorriendo los caminos: ¿activismo femenino excluyente?}

Recorriendo los caminos significa dar una mirada al pasado, mirar lo que hicieron las mujeres en otros contextos y las mujeres colombianas por el reconocimiento de sus derechos, y cómo se movilizaron para conseguirlos. Representa la mirada al pasado para entender el presente.

Las teorías clásicas de la acción colectiva, a pesar de aportar varios elementos que sirven para analizar y entender la acción de las mujeres afrodescendientes de la RNMAK, se quedan cortas al querer explicar por qué se reúnen las mujeres (de Miguel, 2001), particularmente, las mujeres afrodescendientes.

Solo gracias la aparición del feminismo, se empezó a hacer un análisis de la situación que experimentan las mujeres como sujetos sociales, al incluir en la matriz de análisis otras categorías como el sistema sexo-

17 Tomado de la Cartilla de Memorias de la IV Asamblea de la RNMAK, celebrada en el año 2006. 
género, el patriarcado, las mujeres como dueñas de sus cuerpos y la esfera de lo público y lo privado de las mujeres como reflejo de la vida cotidiana, por citar algunos ejemplos. De tal forma que, los feminismos, como teoría crítica, tienen un doble contenido: por un lado, el activismo, y, por otro lado, la teoría académica que empieza a interesarse en el estudio de un nuevo sujeto social y de la acción colectiva, ya no desde la perspectiva de la organización del movimiento o los recursos que utilizan los actores, sino en los actores en sí mismos (de Miguel, 2001; Hill, 2012; Sánchez, 2008).

Para la RNMAK, los aportes de los diversos feminismos han sido importantes en su configuración como movimiento de mujeres; así lo expresa Jobana Millán: "Nosotras, lo que hablamos que va con la Red son los aportes de los movimientos feministas; nos articulamos a esos movimientos” (Comunicación personal, 15 de agosto de 2015).

En su artículo, "Feminismo un movimiento crítico", Justa Montero (2006) se refiere a este asunto así:

El conflicto al que me he referido requiere y define un nuevo sujeto social, las mujeres, que vertebran y protagonizan la acción colectiva de denuncia y contestación a los límites que a su libertad establece la sociedad patriarcal, en una dinámica de transformación profunda de la sociedad (p. 169).

Particularmente, el feminismo negro estadounidense introduce el concepto de interseccionalidad, que se refiere a las múltiples discriminaciones que sufren las mujeres afrodescendientes por su condición de género, raza/etnia, clase, que las diferencian de las opresiones que sufren otras mujeres. Para el caso específico de las mujeres afroamericanas, el análisis interseccional basado en el género, la clase y la etnia, incluye sus narrativas como sujetos de una historia distinta a la de las mujeres de la clase media y blancas que iniciaron el feminismo en Estados Unidos en un contexto de abolicionismo de la esclavitud y lucha por el sufragismo 
(Jabardo, 2012), así como una historia distinta del feminismo europeo permeado por la Ilustración.

Las diferentes etapas de la historia en que han surgido los feminismos dan cuenta de la diversidad que existe dentro de los mismos, de las luchas de las mujeres negras por ganar espacios para el reconocimiento de sus particularidades y exponer dos situaciones que las afectan y que el feminismo blanco no tiene en cuenta: la colonización y el proceso de esclavización (Sánchez, Beltrán y Álvarez, 2008).

La lucha de las mujeres afroamericanas comienza con la abolición de la esclavitud a finales del siglo XIX y el sufragismo de principios de siglo $\mathrm{Xx}$, movimientos que ya presentaban las dicotomías existentes entre mujeres blancas y afroamericanas, pues, en ellos, fueron excluidas las demandas de las mujeres negras, quienes muchas veces fueron obligadas a marchar separadas de la mujeres blancas y obtuvieron el derecho al voto con posterioridad, por lo cual surgió el black feminism en los años sesenta. Sobre este último, profundizaré con mayor detalle, ya que aporta la perspectiva interseccional para entender la realidad de las mujeres negras (Duby y Perrot, 2000; Sánchez, 2008).

\section{Black feminism o feminismo negro norteamericano}

Una de las grandes críticas al feminismo hegemónico norteamericano en los años sesenta fue presentada por las mujeres afroamericanas, quienes señalaban la necesidad de incluir sus vivencias y realidades en los análisis y en las luchas de las mujeres estadounidenses. De esta manera, surge el black feminism como reproche a la exclusión de las mujeres negras del discurso del feminismo (Hill, 2012; Colazo, 2009). A la par, tienen origen otros feminismos como, por ejemplo, el feminismo radical, el feminismo de la diferencia, el feminismo institucional, el ecofeminismo, entre otros (Varela, 2008).

El feminismo negro estadounidense tiene como principal objetivo que las mujeres negras se empoderen de la injusticia social que representan 
las opresiones interseccionales, dadas por el género, la clase y la etnia/ raza, pues son víctimas del racismo que ha impuesto históricamente el proceso de esclavización y de las políticas de segregación racial que se establecieron en los Estados Unidos. Para Hill (2012), esto se constituye en un proyecto de justicia social en favor de la dignidad humana, que tiene como principio rector una permanente perspectiva humanista.

Esta autora señala que las mujeres afroamericanas que sufren el racismo constante no pueden relacionarse con sus vecinos blancos ni pueden ir a sus mismas escuelas y son perseguidas en las tiendas por los vigilantes como si fueran a robar algo. Asimismo, expone que dichas experiencias son comunes a las mujeres negras en todo el mundo y que el feminismo estadounidense permite una conexión entre la experiencia de las mujeres afrodescendientes de manera individual y su activismo para generar una conciencia de grupo, lo que, a su vez, fomenta una conexión entre el activismo y el feminismo como teoría crítica (p. 103).

Actualmente, las mujeres afrodescendientes de la RNMAK siguen promoviendo la idea de analizar de manera diferencial la realidad de las mujeres afrodescendientes y la de otras mujeres. Así lo expresa Deyanira, miembro de la RNMAK, cuando dice que "no podemos marcar a la mujer negra en el mismo costal, tenemos unas particularidades y tenemos unas especificidades que no las tiene el resto de mujeres [...]" (Comunicación personal, 17 de agosto de 2015).

\section{Encuentro de puntos comunes para mujeres de ascendencia africana: el feminismo en la Red Nacional de Mujeres Afrocolombianas Kambirí}

En la academia y en la lucha política, el feminismo negro ha servido para entender y reconocer una especie de opresión común que sufren las mujeres negras en diversas partes del mundo, lo que ha permitido que se sientan identificadas con esas formas de describir y teorizar la opresión de las mujeres afrodescendientes. Al respecto, Patricia Hill 
Collins (2012) señala que: "En general, estos vínculos entre lo que una hace y lo que piensa, ilustrados por mujeres negras individuales, también pueden caracterizar las experiencias e ideas de las mujeres negras como grupo" (p. 104).

En razón a lo anterior, este artículo toma las definiciones y aportes del feminismo negro estadounidense como una línea teórica útil, para entender lo que sucede dentro de la RNMAK, sus relaciones como red y con otros actores, y cómo esta emprende la acción colectiva a partir del reconocimiento de ser afrodescendientes. Con este objetivo, tengo en cuenta la definición de feminismo negro planteada por Collins, citada por Sánchez (2008):

Sugiero que el pensamiento feminista negro consiste en un conocimiento especializado, creado por mujeres afroamericanas que clarifica [SIC] un punto de vista de y para mujeres negras. En otras palabras, el pensamiento feminista negro se compone de interpretaciones teóricas sobre la realidad de las mujeres negras, elaboradas por quienes viven esa realidad (p. 278).

Como mencioné, el feminismo negro es interesante, porque permite entender las relaciones que surgen en la RNMAK y une la historia de las mujeres negras, sus opresiones y sus formas de habitar el mundo, de tal forma que conjuga "el conocimiento, la conciencia y las políticas de empoderamiento" (Jabardo, 2012, p. 35). Por lo mismo, es capaz de explicar el activismo de las mujeres afrodescendientes y, en este caso, de la RNMAK ${ }^{18}$, Desde su pasado histórico común, desde los sueños de libertad de los antepasados secuestrados de África, hasta las opresiones actuales de las que son víctimas en su condición de mujeres,

18 Hago esta afirmación sin que implique la simplicidad de pensar que dentro del feminismo negro no hay críticas. Mucho menos propongo pensar que, como vivencia y teoría desde el feminismo negro estadounidense, se expliquen todas las realidades de las mujeres afrocolombianas de la RNMAK. 
afrodescendientes, desplazadas, pobres, y su búsqueda común de justicia social y de mejores condiciones de vida.

En esa misma dinámica, el feminismo negro aporta dos conceptos fundamentales: la interseccionalidad y la sororidad o solidaridad de las mujeres negras.

\section{Confluencia de relaciones, multiplicidad de discriminaciones: la interseccionalidad}

La interseccionalidad surge por primera vez en el marco del movimiento sufragista y antiesclavista de finales del siglo XIX. Aunque no tenía esa denominación en aquel entonces, las feministas negras de esa época, como Ida Wells y Sojourner Truth, fueron quienes empezaron a hacer la relación de las discriminaciones surgidas de las categorías raza y género; de esta forma, diferenciaron el feminismo negro del blanco (Jabardo, 2012; Sánchez, 2008).

En los albores de los años setenta, en el marco del feminismo negro estadounidense, apareció el análisis de las opresiones surgidas del género, la clase social y la etnia/raza, bajo la denominación de interseccionalidad (Colazo, 2009; Cubillos, 2015; Hill, 2012; Viveros, 2016). Este término denota una matriz de dominación diferente para las mujeres afrodescendientes, cuya realidad hace evidente otros problemas no solo por ser mujeres, sino por su condición de clase y la discriminación racial de la que son víctimas. Por lo mismo, el movimiento feminista tuvo que repensar la forma en que estaba universalizando el término "mujer" y la forma en que teorizaba al hablar por todas las mujeres, con lo cual obviaba la realidad de las mujeres afrodescendientes y de otras mujeres como las indígenas y las latinas, entre otras (Hill, 2012; Viveros, 2016).

En la entrevista, Deyanira plantea esa interseccionalidad que permea la vida de las mujeres afrodescendientes —específicamente de la RNMAKde forma clara: 
Realmente, nosotras, como mujeres negras, llevamos unas cargas horribles en los hombros. No solo ser personas no adineradas, porque yo no le llamo pobres, porque ese término no me gusta, sino vulneradas. Además de ser negras de por sí, que le adiciona abrirnos espacios como sea, el ser mujeres. Esas tres cosas son una carga bastante pesada. A eso tiene que añadirle el ser cuidadoras por naturaleza, la responsabilidad de un hijo que no va a estar sobre el hombro del esposo; puede ser el mejor hombre del mundo, pero esa responsabilidad te la deja a ti (Comunicación personal, 15 de agosto de 2015).

En esta entrevista, Deyanira expresa las múltiples opresiones interseccionales que recaen sobre la mujer negra: el género, la clase social y la etnia/raza. En ese sentido, la RNMAK, en su lucha por posicionar los asuntos de las mujeres negras con enfoque interseccional, celebró en agosto de 2016 su viII Asamblea, que tuvo como principal objeto ser un "encuentro nacional de mujeres negras, afro, raizales palenqueras por la paz y la reconciliación”. En el segundo día, se organizaron mesas de trabajo sobre diversos temas, entre ellos, “derechos humanos y mujeres negras", en la cual tuve la oportunidad de participar. Como producto de la relatoría, surgió la siguiente conclusión:

El Estado colombiano, a través de la Constitución, habla de respeto por las diferencias, de equidad, igualdad, pero, en la realidad práctica, continuamos siendo discriminadas y relegadas de los espacios de decisiones; se hace necesario que estemos y permanezcamos organizadas para que la defensa de los derechos sea efectiva. Se deben hacer plantones, pronunciamientos, marchas, denuncias, salir a las calles y hacer visibles los atropellos que se comenten contra todas las mujeres y en particular las mujeres negras, que somos triplemente discriminadas, excluidas, victimizadas y marginadas por muchos factores. Debemos apropiar lo que se establece a través de la legislación que nos beneficia en todos los sentidos, solicitar capacitaciones, asesorías que contribuyan al despertar de otras mujeres que en los territorios requieren de ayuda para iniciar sus procesos organizativos o articularse a sus luchas reivindicativas, históricas, étnicas, territoriales 
y de género. No podemos desfallecer en el intento, mujeres negras somos poder, transformación, cultura y esperanza, exijamos nuestros derechos ${ }^{19}$.

Se observa cómo las mujeres de la RNMAK evidencian lo que ellas llaman triple discriminación en relación con las opresiones interseccionales de las que son víctimas, al ponerlas dentro de la agenda de acción del 2017, posicionar las acciones de la Red y tener presente que se debe trabajar para eliminar no solo las acciones discriminatorias en razón del género, sino también aquellas basadas en la raza y la clase.

Figura 2. VIII Asamblea de la RNMAK

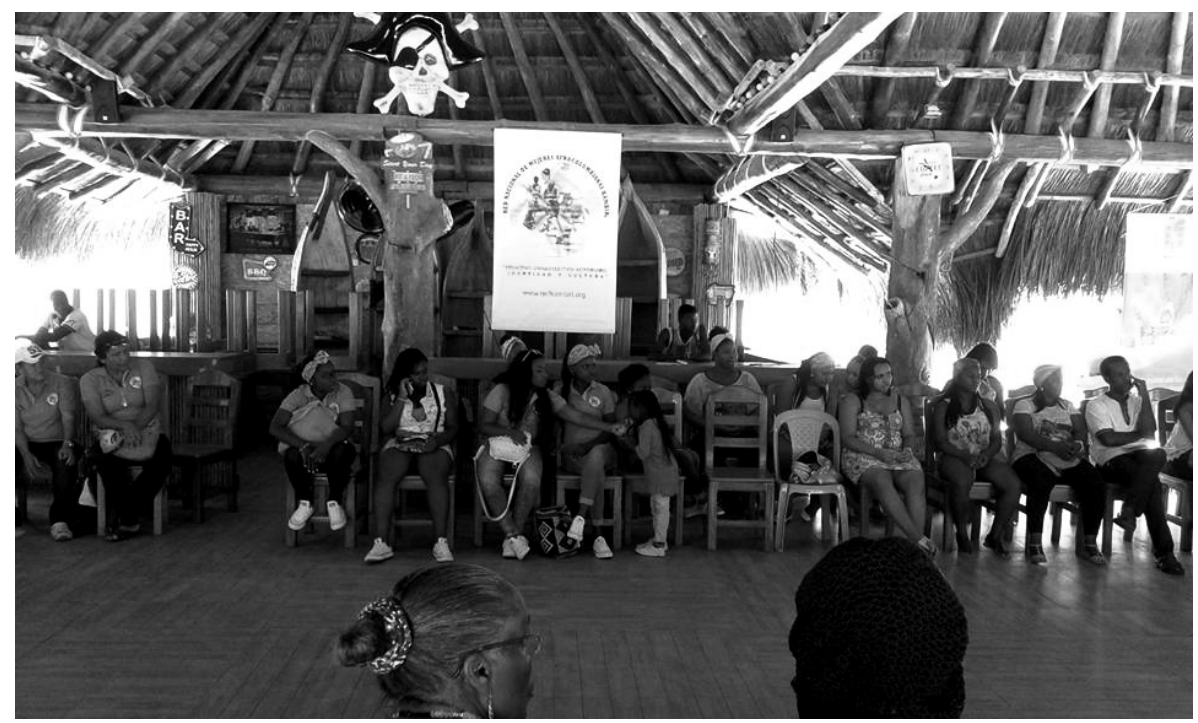

Fuente: fotografía tomada por Diana Carolina Angulo Ramírez el 8 de octubre de 2016. En este espacio de asamblea, es donde las mujeres de la RNMAK comparten sus experiencias desde cada región y promueven la construcción de conocimiento.

Tomasa Medrano también hizo un llamado a identificar esas múltiples discriminaciones, cuando señala en su ponencia "Proceso organizativo",

19 Tomado de la Relatoría de la VIII Asamblea de la RNMAK, remitida por Tomasa Medrano a través de correo electrónico el 5 de diciembre de 2016. 
presentada en la IV Asamblea de la RNMAK, que las mujeres afrodescendientes:

Estamos llamadas a la unidad para derrotar el racismo, la discriminación en toda su gama, el analfabetismo, los abusos, las violaciones, el machismo, la indiferencia estatal y a obtener el derecho a una vida digna, al respeto hacia nuestro cuerpo y nuestras cosmovisiones, al fortalecimiento de la identidad cultural, la participación con equidad en los espacios de toma de decisiones, la inclusión en planes, programas y proyectos sociales desde nuestras particularidades ${ }^{20}$.

A pesar de que algunas de las mujeres de la RNMAK se consideran feministas, no ocurre de igual forma con todas las mujeres que integran la Red, como lo expresa Jobana Millán:

Del movimiento feminista retomamos algunos elementos, como lo hace la Ruta Pacífica de Mujeres, que es un movimiento feminista también, pero digamos que realmente, a conciencia, las mujeres que lideran el proceso saben qué es el feminismo y algunas nos consideramos feministas. Pero, si vamos a hablar de la Red como tal, dentro de su proceso, las mujeres locales, aquellas que hacen parte integral, todavía ese concepto del feminismo no lo tienen atravesado por su cuerpo. Ellas saben que son mujeres que luchan por los derechos de las mujeres y que trabajan por sus derechos, por sus reivindicaciones, pero digamos que no tienen un concepto o una claridad sobre el feminismo (Comunicación personal, 15 de agosto de 2015).

No obstante, desde su perspectiva como mujeres afrocolombianas, ellas identifican las discriminaciones interseccionales de las que son víctimas y dentro de su plan de acción establecen como prioridad el empoderamiento de las mujeres afrodescendientes de la RNMAK, a través de la formación educativa, el conocimiento de la historia de los afrodescendientes en América y la participación política como forma de combatir

20 Tomado de la Cartilla de Memorias de la IV Asamblea de la (RNMAK), celebrada en el año 2006. 
esas múltiples opresiones interseccionales. Estas últimas se han intensificado debido a que el patriarcado racista, machista y excluyente, se niega a perder el poder y pretende mantener el statu quo mediante la Iglesia, los medios de comunicación y el resurgimiento de los nuevos grupos políticos de derecha, que pretende retroceder en los avances alcanzados a través de los derechos humanos.

En este acápite, mostré cómo la Red ha tomado del movimiento negro estadounidense el concepto de interseccionalidad, para entender sus problemáticas de forma holística, así como su utilidad, para poder entender sus realidades, ya que estas son experiencias de mujeres negras contadas por ellas mismas y este es un proyecto que dignifica a la población afro tras las múltiples injusticias que ha sufrido. Así, en línea de pensamiento deductivo, voy de lo general del movimiento de mujeres afro en otras latitudes a analizar lo particular del movimiento negro en Colombia y cómo han surgido otras organizaciones de mujeres que promueven las luchas desde el análisis interseccional y los derechos humanos.

\section{El movimiento negro en Colombia, la invisibilidad de las mujeres afrodescendientes}

En este apartado, presento de manera sintética la movilización que se ha llevado a cabo dentro del movimiento negro en Colombia y cómo aparece la RNMAK como una red que propende por la lucha de los derechos humanos de las mujeres afrocolombianas.

En Colombia ha existido una invisibilidad del estudio de la población afrocolombiana y aún más de las mujeres afrocolombianas en la academia; fue a partir de los estudios de Nina S. Friedemann que comenzó el interés por los estudios de la población afrocolombiana (Lamus, 2012).

Las mujeres afrodescendientes ya estaban inmersas en las luchas del movimiento afrocolombiano que se gestó en los años setenta, en 
el Primer Encuentro Nacional de la Población Negra Colombiana, celebrado en 1975, en el cual, se destaca la participación de Adelina Abadía Villegas (Wabgou et al., 2012). Se considera que este evento fue un hito, dado que no se habían realizado eventos de esa magnitud para reivindicar las demandas del pueblo afrodescendiente.

A este evento le siguieron varios encuentros nacionales, que fueron los repertorios de acción del Movimiento Social Afrocolombiano, como el Segundo Encuentro Nacional de la Población Negra Colombiana, en Quibdó en 1976; el III Encuentro de Regional y I del Litoral Pacífico, en Tumaco en 1975; el Congreso de Negritudes, en Medellín en 1977; el Tercer Encuentro Nacional de la Población Negra Colombiana, en Cartagena en 1977 y el Primer Congreso de la Cultura Negra de las Américas, en Cali en 1977. A estos encuentros, se sumó la creación de varias organizaciones en pro de la defensa y reivindicaciones del pueblo afrodescendiente, en las cuales resultó vital la participación de los estudiantes y afrodescendientes vinculados al magisterio (Wabgou et al., 2012).

Para los años ochenta, el movimiento afrodescendiente se manifiesta y protesta a través de paros cívicos, varios de los cuales se desarrollaron en ciudades como Quibdó y Tumaco, para solicitar al Estado la mejora en la prestación de los servicios públicos. Sin embargo, para este momento, aún no se ponen en la agenda pública del Movimiento Social Afrocolombiano las apuestas particulares de las mujeres, ya que, en principio, la gran apuesta apuntaba a las reivindicaciones étnicas e identitarias como un solo pueblo.

La Constitución de 1991 es, en los años noventa, la que marca una pauta distinta para el movimiento social afrocolombiano, que se vuelca a la reglamentación del artículo transitorio 55, para la expedición de la Ley 70 de 1993 (Pardo, 2001). En ese entonces, las reivindicaciones tienen que ver con los derechos territoriales sobre las tierras que han habitado las comunidades negras y con la implementación de los programas de 
etnoeducación (Restrepo, 2004). Pero esto no se dedica a las demandas particulares de las mujeres afrodescendientes, lo que se explica porque, a pesar de que el Movimiento Social Afrodescendiente estaba conformado por hombres y mujeres, las aspiraciones estaban concentradas en su reconocimiento como grupo étnico y en la lucha contra la discriminación racial que afectaba a ambos sexos; asimismo, la diversidad de género dentro del movimiento aún no era un motivo de preocupación.

Con posterioridad a la Constituyente, se empiezan a crear colectivos específicos de mujeres afrocolombianas, ya que no veían reflejados sus intereses dentro de las organizaciones de conformación mixta, es decir, conformadas por hombres y mujeres afrocolombianos: "una recurrente situación en varios relatos es la de la separación de las mujeres de algunas organizaciones mixtas por los particulares estilos patriarcales de sus líderes" (Lamus, 2012, p. 85). Por este motivo, empezaron a crearse organizaciones como la Red de Mujeres Negras del Pacífico, que nació en 1992, definida como "un conjunto de grupos que se unen para apoyarse mutuamente en la búsqueda de soluciones a las situaciones que afectan a la comunidad negra en general y en particular a las mujeres, identificando en esta situación su triple discriminación como mujeres, negras y pobres" (p. 71).

Así mismo, aparece la Red Departamental de Mujeres Chocoanas en 1992, con la clara intención de reivindicar la situación de las mujeres afrocolombianas, desde el género y la etnia, y posicionarse en los espacios públicos. Su objeto social

se basa en la promoción de la mujer chocoana y sus organizaciones, formando líderes capaces de potenciar desde su acontecer en la construcción de relaciones de equidad entre hombres y mujeres, contribuyendo al desarrollo social sostenible, logrando la transformación individual y colectiva a través de mecanismos de formación y capacitación ${ }^{21}$.

21 Para mayor información, véase: http://www.asociacionicid.org/index.php/colombia/36red-departamental-de-mujeres-chocoanas. 
Por otro lado, el Proceso de Comunidades Negras (PCN) y de la Asociación de Afrocolombianos Desplazados (Afrodes) son organizaciones de carácter mixto, que crearon líneas de trabajo sobre el tema de género tras debates dentro de las organizaciones (Lamus, 2012). En este ambiente surge, en el año 2000, la RNMAK, un colectivo de mujeres afrocolombianas de diversos procesos sociales del movimiento social afro, como señala Tomasa:

Cada una de las mujeres que hacemos parte de la Red, hicimos parte, anteriormente, de diversos procesos organizativos afrocolombianos, no necesariamente de Cimarrón; Cimarrón es solo uno de esos procesos. En mi caso, yo hacía parte de Cimarrón, pero otras compañeras venían de otros procesos, no es que la Red nació de Cimarrón, sino que nosotras hacíamos parte de ese proceso y dentro del proceso Cimarrón no sentíamos representado nuestro liderazgo (Comunicación personal, 22 de junio de 2016).

Como se evidencia, la Constitución de 1991 y el reconocimiento de derechos a la población afrodescendiente abren un nuevo escenario, en el cual, las reivindicaciones del pueblo afro cobran relevancia y de allí toman fuerza los movimientos de mujeres afrodescendientes. Muchos de estos estiman que la opresión de género también está presente en los escenarios compartidos con los hombres de su etnia, razón por la cual se ven abocadas a conformar procesos independientes que les permitan evidenciar sus propias problemáticas.

Sin embargo, el tema de la lucha por los derechos humanos del pueblo afrodescendiente y de las mujeres afrocolombianas no canta a una sola voz su reivindicación. Otras voces promueven discursos cargados de odio y quieren deslegitimar las luchas de las mujeres, de las comunidades afrocolombianas, los pueblos indígenas y otros colectivos como los movimientos LGBTI, al señalar que tales reconocimientos y "prebendas" -en referencia al goce de sus derechos- no son necesarios en la sociedad. Estos se preguntan: ipor qué existen acciones afirmativas solo para estos colectivos? De esta manera, obvian las luchas históricas y 
las brechas generadas por el proceso de esclavización y la colonización, para algunos, y desconocimiento de sus derechos, dada su condición de minoría y la diferencia de los patrones sociales de género, etnia y clase; pero, sobre todo, ellos dejan de lado el proceso reivindicador que emprendieron dichos colectivos en pro del reconocimiento de sus derechos humanos.

En razón a lo anterior, en el siguiente apartado presento la relevancia de los derechos humanos como la herramienta jurídica vinculante, con la que cuentan las mujeres afrocolombianas y otros colectivos sociales, para exigir al Estado su reconocimiento como sujetos de derechos y en el consecuente ejercicio de los mismo. Esto ocurre en un momento histórico, en el cual, algunas personas con ansias de poder proclaman un discurso, que propone dirigir el orden internacional hacia los autoritarismos, los nacionalismos, los sectarismos, aun con todas las peligrosas consecuencias que estos giros comportan como el resurgimiento de los grupos de extrema derecha, la xenofobia, el racismo, el machismo y la aceptación de estos comportamientos sociales reprochables, que asumíamos en descenso y que en los últimos años han tomado fuerza internacional y en la región.

\section{Los derechos humanos: la bandera para superar escenarios injustos}

Durante los años sesenta, el discurso de los derechos humanos se globalizó, lo que permitió, por ejemplo, la visibilización a nivel mundial de la lucha por los derechos civiles de los afroamericanos, la abolición del Apartheid en Sudáfrica y el movimiento de mujeres de los años sesenta en Estado Unidos; esto hizo que el mundo de Occidente pusiera los ojos en situaciones que se consideraron injustas. El propósito era lograr que las demandas de estos grupos fueran oídas, que se tuvieran en cuenta en la agenda pública internacional y encontraran eco en sus países de origen, para, finalmente, lograr la expedición de leyes que les dieran derechos y reconocimiento como ciudadanos. Keck y Sikkink 
(1998) explican este acontecimiento como el efecto bumerang, que consiste en que un "Estado A bloquea las organizaciones que se encuentran dentro de él; estas activan la red, cuyos miembros ejercen presión sobre sus respectivos Estados y (si viene al caso) acuden a una tercera organización, que a su vez ejerce presión sobre el Estado A” (p. 31).

Así, la lucha por los derechos de las mujeres se convirtió en una causa mundial, que permitió que en otras partes del mundo las feministas iniciaran protestas como estrategia política y de movilización social para exponer aspectos que consideraban injustos en cada uno de sus países. La realidad activista y teórica de las mujeres afroamericanas procuraba evidenciar que la lucha por los cambios en el sistema patriarcal debía estar en clave de género, etnia/raza y clase; esto se debe a que la experiencia de las mujeres negras muchas veces resultaba diferente gracias a su color piel y a su condición de pobreza, como lo señala Collins (2012):

En particular, el pensamiento y la práctica feministas negros responden a una contradicción fundamental en la sociedad estadounidense. Por un lado, las promesas democráticas de libertad individual, igualdad ante la ley y justicia social hechas a todos los ciudadanos, pero, por otro lado, persiste la realidad del trato grupal diferencial basado en la raza, la clase, el género, la sexualidad y el estatus de ciudadanía. Los grupos organizados alrededor de la raza, la clase y el género en y por sí mismos no son inherentemente un problema. Sin embargo, cuando los afroamericanos, la gente pobre, las mujeres y otros grupos discriminados, tienen poca esperanza de que su grupo mejore, esta situación constituye una injusticia social (p. 102).

En relación con la reflexión desarrollada por Collins, es importante resaltar que el reconocimiento de los derechos de los pueblos afroamericanos ha estado provisto de las luchas, a través de las acciones emprendidas por los movimientos sociales. Por lo mismo, la teoría de los derechos humanos se constituye en una herramienta para evidenciar la injusticia social que significaba la negación de derechos a las personas debido a su condición racial y de género, problema que ha sido catapultado hasta lograr establecerse en la agenda pública mundial. 
Por otro lado, el mundo académico empieza a revisar de modo crítico la teoría de los derechos. Algunos de estos estudios se preguntan: ison los derechos humanos realmente universales?, ison universales para todos los pueblos del mundo?, ¿qué significa la dignidad humana?, ¿los derechos alienan o liberan a los individuos? (de Sousa Santos, 1998). Estas preguntas han sido analizadas dentro de los estudios críticos de derechos, como lo describe Isabel Cristina Jaramillo en la introducción del texto titulado La crítica de los derechos.

A continuación, presento algunas reflexiones al respecto, a modo de contraste entre quienes defienden los derechos como eje central de la acción colectiva -como las mujeres afrodescendientes-y los autores que plantean la inutilidad de ese discurso.

\section{Significado de la lucha por los derechos humanos: reflexiones sobre la teoría de los derechos}

Desde la teoría política, existen tres grandes críticas a la teoría de los derechos. La primera hace énfasis en que los derechos reivindican las libertades y la igualdad formales de las personas como ciudadanos y no como comunidades. Es decir que la formalidad de los derechos es una abstracción que no permite que exista una experiencia real con una comunidad que reconozca a ese otro como portador de derechos; así, los derechos terminan siendo una abstracción individual (Jaramillo, 2003).

La segunda crítica considera que los derechos alienan, dado que el propio sistema legal obliga a las personas a que su vida sea un resultado del derecho. Asimismo, el derecho regula las relaciones de las personas, al hacer que las interacciones sociales se sujeten a lo establecido en las normas; por ello, para Jaramillo, "los derechos, en ese sentido, implican entender al individuo como un vehículo vacío que debe ser llenado con derechos y así reemplazar el momento activo del deseo con la posibilidad pasiva de tener derechos" (p. 21). Adicionalmente, al citar a Peter Gabel, Jaramillo señala que la experiencia de los derechos está 
dada como un regalo, ofrecido por otro, que es el Estado, argumento que llama mi atención, puesto que sostengo que la lucha por los derechos de las mujeres afrocolombianas ha sido producto de su incesante pugna por ser reconocidas, desde el terreno legal que lo legitima y la sociedad que respeta y reconoce en el otro un sujeto con derechos.

La tercera crítica muestra que el discurso de los derechos no es universal, aunque se intente presentar como tal. En esa medida, la autora expone que este tiene dos vertientes: la primera está orientada a señalar que la experiencia de los derechos ha sido solo de los hombres blancos, burgueses y protestantes; la otra indica que los derechos son solo la experiencia de quienes detentan más poder que otros y que la ambición de universalidad en sí misma es imperialista.

Al referirse a la crisis del derecho, Teubner (2005) afirma que la pretensión de universalidad de este hace que no se ajuste a los problemas de una "sociedad altamente diferenciada", lo cual se debe a que el sistema legal carece de herramientas adecuadas para las "demandas de planeación y de política social” de la sociedad (pp. 123-129).

Por su parte, Bourdieu (2005) señala que la universalidad del derecho en una sociedad altamente diferenciada es uno de los instrumentos mediante los cuales los más poderosos ejercen "dominación simbólica" para imponer un cierto orden social. En ese sentido, las normas jurídicas tienden a imponer el estilo de vida del dominador o lo que el autor denomina el efecto normalizador del derecho.

A pesar de las críticas al discurso de los derechos, existen otros autores que siguen defendiendo la lucha de los movimientos sociales por su reivindicación y la importancia de las minorías étnicas que continúan trabajando por su reconocimiento legal. Al respecto, Patricia Williams (2003) afirma que “[...] la percepción que uno tiene de su propio poder define la relación con el derecho en términos de confianza/desconfianza, formalidad/informalidad, derechos/no derechos" (p. 48). 
La experiencia de la gente afrodescendiente en el uso del discurso de los derechos ha permitido que sean reconocidos como un "otro", es decir, como un sujeto con derechos y no como un objeto. Así que, para Williams, la crítica de los derechos dependerá del lado de la historia en el que se haya estado: claramente, a una persona "blanca" le será más fácil asumir o expresar que el discurso de los derechos es alienador. No obstante, la experiencia de la gente afroamericana, afrodescendiente, afrocolombiana, a través del discurso de los derechos es que "[...] ha sido y continúa siendo una forma efectiva de discurso" (49). Entonces, para la población afrocolombiana, las leyes que se han expedido ${ }^{22}$ en favor tanto del reconocimiento de su libertad como de sus derechos, han sido producto de la lucha histórica por acabar con la situación fáctica de abuso y sumisión y con la condición mental de inferioridad, bajo la cual estuvo catalogada la población africana en distintas partes del mundo.

Por eso, para la población afrocolombiana, el reconocimiento de derechos en un país que se los había negado implicó, por un lado, un proceso reaccionario de resistencia, y, por otro, un proceso legal. Así, el discurso de los derechos es una premisa fundamental en la lucha y un

22 Desde el siglo XIX, se empezaron a expedir leyes que trataban de regular la situación en que se encontraba la población esclavizada, como la ley de vientres o la manumisión, que fueron leyes que trataban de proteger más el derecho de propiedad sobre el esclavizado que a garantizar el derecho a la libertad (Díaz, 2015). En el siglo Xx, con la expedición de la Constitución de 1991, se empieza a dar otra mirada jurídica y a expedir otras normas que han permitido el reconocimiento de los derechos de la población afrocolombiana, como la Ley 70 de 1993, por medio de la cual se desarrolla el artículo 55 de la Constitución Política, que establece la Cátedra de Estudios Afrocolombianos y reconoce acciones afirmativas para la población afrodescendiente, que fueron reglamentadas con posterioridad. Entre las anteriores, están la Ley 649 de 2001, "Por medio de la cual se reconoce la circunscripción especial para la cámara de representantes"; la Ley 725 de 2001, "Por medio de la cual se estableció el día de la afrocolombianidad"; la Ley 1482 de 2011, "Por medio de la cual se penaliza la discriminación racial y por condición de género", entre otras. Para mayor información, revisar la página de la Presidencia de la República: http:// wsp.presidencia.gov.co/afrocolombianos/programa/Paginas/normativa.aspx 
motor para la acción colectiva de los pueblos afrodescendientes, como escribe Williams (2003):

Para los negros, entonces, la batalla no es la de la deconstrucción de los derechos en un mundo de no derechos; tampoco la de construir afirmaciones sobre necesidades, en un mundo de abundantes y obvias necesidades. Más bien, el objetivo es encontrar un mecanismo político que pueda enfrentar la negación de la necesidad. El argumento de que los derechos son inútiles, incluso perjudiciales, trivializa este aspecto específico de la experiencia negra, así como la de cualquier persona o grupo cuya vulnerabilidad ha sido verdaderamente protegida por los derechos (p. 53).

En ese mismo sentido, De Sousa (1998) señala que los derechos humanos deben ser cosmopolitas ${ }^{23} \mathrm{y}$ multiculturales. Afirma que, "en todo el mundo millones de personas y millares de ONG han luchado por los Derechos Humanos, muchas veces corriendo grandes riesgos, en defensa de clases sociales y grupos oprimidos, y en muchos casos victimados por Estados capitalistas autoritarios” (pp. 20-21). Agrega que estos discursos, dentro de los cuales está la defensa de los derechos de las mujeres, se construyeron como discursos alternos, que fueron proponiendo miradas no occidentales de los derechos humanos, por eso, "[...] la tarea central de la política emancipatoria de nuestros tiempos consiste en transformar la conceptualización y práctica de los derechos humanos de un localismo globalizado ${ }^{24}$ en un proyecto cosmopolita" (p. 21).

23 El autor define el término cosmopolita como aquel proceso social en el que, a pesar de existir unas formas de dominación, surgen grupos, alianzas, asociaciones de personas a nivel internacional que intentan cambiar ese orden de cosas establecido por el sistema mundial, a través de grupos feministas, organizaciones jurídicas de asistencia alternativa, movimientos ecologistas, "en busca de valores culturales alternativos, no imperialistas, dedicados a estudios con perspectivas poscoloniales o subalternas" (de Sousa Santos, 1998).

24 El localismo globalizado "es el proceso mediante el cual determinado fenómeno local se globaliza con éxito” (de Sousa Santos, 1998). 
En Occidente, los derechos humanos son vistos como una teoría globalizada o globalizante o como discursos y prácticas universales o relativos. Sin embargo, no se puede negar que aportaron de forma sustancial en la defensa de la situación de injusticia en la que se encontraba la población afrodescendiente en el mundo; por eso, los derechos de la población afrocolombiana son un logro y no un regalo.

Para el caso de las mujeres afrocolombianas de la RNMAK y de otras minorías en el país, el reconocimiento de sus derechos ha sido la consecuencia de la lucha en la arena social y política para ser reconocidos como sujetos con derechos y conseguir, a través de la acción colectiva, la dignidad humana que el proceso de esclavización, dominación y colonización les negó. Con base en esta reflexión, cabe anotar que los derechos de los que hoy gozamos son parte del proceso histórico de lucha, construcción de ciudadanía y reconocimiento del otro, como resultado de las acciones emprendidas por los diversos movimientos sociales. Un ejemplo de esto es el Movimiento Social Afrocolombiano, que, a través de la Constitución de 1991, luchó como grupo étnico por el reconocimiento de los territorios que tradicionalmente habitan y por el derecho a la etnoeducación (Pardo, 2001; Restrepo, 2004).

\section{Conclusiones}

En este artículo he presentado cómo surge la RNMAK en el escenario nacional y en el marco del surgimiento del movimiento negro en Colombia partir del reconocimiento de los derechos, consagrado en la Carta Política de 1991. Así mismo, expuse la manera en que emprenden las mujeres afrocolombianas de la RNMAK los procesos de acción colectiva, desde la interseccionalidad las categorías, étnica, género y clase, para el posicionamiento de los temas de las mujeres afrocolombianas en la agenda pública. De esta forma, ellas expresan la pluralidad de sus intereses como grupo, los diferencian de otros grupos de mujeres y logran establecer su agenda política para la reivindicación de sus derechos. 
Aun cuando como colectivo no manifieste un vínculo con un tipo de feminismo en particular, sino con los movimientos feministas, en el caso específico de la RNMAK, el activismo del feminismo negro estadounidense, que surge desde la experiencia misma de las mujeres afroamericanas en las calles - como grupo oprimido, en contraposición a las injusticias sociales que vivían-, ha servido de fundamento para las mujeres miembros, así como para aquellas de descendencia africana en todo el mundo. Como resultado, ellas han podido encontrar una forma de luchar contra las opresiones interseccionales que las aquejan, ya que tienen puntos comunes como el pasado histórico, el género, la etnia, la clase social; de igual modo, en muchos casos, las injusticias que viven son similares, como la violencia intrafamiliar, la falta de oportunidades, la discriminación racial, entre otras.

En razón a lo anterior, el feminismo negro estadounidense brinda la oportunidad de entender la realidad de las mujeres de la RNMAK, porque es un proyecto de justicia social, en el que otros grupos - como las mujeres negras, las latinas, las mestizas, los hombres negros, los grupos étnicos- identifican vínculos que los conectan y que contribuyen a su proyecto de red como marco de justicia social. En ese sentido, la interseccionalidad como categoría de análisis hizo posible la comprensión de las múltiples situaciones de exclusión y marginalidad que viven las mujeres afrocolombianas de la Red y su diferenciación con las opresiones vividas por otras mujeres como las mestizas, las indígenas y las blancas. En consecuencia, esto faculta que su acción colectiva se dirija también a eliminar o atacar dichas opresiones.

Entonces, la interseccionalidad posibilita la reflexión acerca de las circunstancias de racismo y exclusión en torno a las mujeres afrocolombianas como individuos, en su subjetividad, y a las opresiones experimentadas a nivel estructural en la sociedad, a través de sus instituciones. A su vez, la RNMAK practica el activismo desde el reconocimiento de los derechos humanos como discurso, a fin de dar conocer dichas discriminaciones y atacarlas mediante diversas expresiones jurídicas. 
Es importante destacar que los derechos de los que hoy gozamos son parte del proceso histórico de lucha, de construcción de ciudadanía y de reconocimiento del otro, gracias a la acción colectiva de diversos movimientos sociales. En el caso del Movimiento Social Afrocolombiano, su pugna por el reconocimiento como grupo étnico - a través de la Constitución de 1991 y la Ley 70 de 1993- y de los territorios tradicionalmente habitados, y por el derecho a la etnoeducación, son algunos de los logros que conlleva la etnicidad como una estrategia política. Así mismo, se hace necesario revisar a profundidad, en perspectiva y prospectiva, los feminismos actuales como movilizadores sociales y de canal, para buscar reformas dentro y fuera de las organizaciones sociales de mujeres en Colombia.

Para finalizar, se hace necesario indicar que, en futuros trabajos, es importante revisar el impacto de los actuales procesos segregacionistas, xenófobos y racistas, y cómo las nuevas tendencias nacionalistas afectan el reconocimiento de los derechos de la población afrodescendientes, en especial aquellos de las mujeres afrocolombianas, tema que puede llegar a ser objeto de posteriores investigaciones.

\section{Referencias}

Archila, Mauricio (2013). Aspectos sociales y políticos de las mujeres en Colombia, siglos XX y XXI. En Memorias del XVIII Congreso de la Asociación de Colombianistas. Recuperado de http://www.colombianistas.org/Congresos /DocumentosyActas/

Archila, Mauricio (2001). Vida, pasión y... de los movimientos sociales en Colombia. En Movimientos sociales, Estado y democracia en Colombia. Bogotá: Universidad Nacional.

Atehortúa, Cruz Adolfo León. y Rojas, Rojas Diana Marcela (2005). Mujer e historia, (7), 279-280. Recuperado de https://bit.ly/2CULbtt

Bolos, Silvia (2008). La construcción y ejercicio de la ciudadanía de las mujeres participantes en organizaciones sociales. En Mujeres y espacio público. Construcción y ejercicio de la ciudadanía, pp. 29-86. México. 
Colazo, Carmen (2009). Feminismos en la América Latina globalizada/localizada. Nuevas democracias, nuevas izquierdas, en deuda con la equidad de género. ¿Un espacio amigable para una utopía posible? Revista Venezolana de Estudios de la Mujer, (14), 105-118.

Crenshaw, Kimberly (1991). Mapping the margins: Intersectionality, identity politics, and violence against women of color. Stanford Law Review, (43), 1241-1299. Recuperado de http://dx.doi.org/10.2307/1229039.

Cubillos, Almendra Javiera (2015). La importancia de la interseccionalidad para la investigación feminista. Oximora Revista Internacional de Ética y Política, (7), 119-137. Recuperado de https://bit.ly/2sdGtR4

Curiel, Ochy (2009). Identidades esencialistas o construcción de identidades políticas: el dilema de las feministas afrodescendientes. Construyendo Nuestra Interculturalidad, (5), 1-16. https://bit.ly/2RcAcnQ

De la Torre, Jenny, Sepúlveda, Candelaria, Marín, Claudia y Berardinelli, Narda (2014). Empoderamiento y participación política de las mujeres negras, afrodescendientes y palenqueras en Colombia. Quito: Oxfam, Agencia Española de Cooperación Internacional para el Desarrollo.

De Miguel, Ana (2001). El movimiento feminista y la construcción de marcos de interpretación: el caso de la violencia contra las mujeres. Revista Internacional de Sociología, (35), 127-150.

De Sousa Santos, Boaventura (1998). Por una concepción multicultural de los derechos humanos/For a multicultural conception of human rights. México D. F.: Universidad Nacional Autónoma de México.

De Sousa Santos, Boaventura (2010). Descolonizar el saber, reinventar el poder. Montevideo: Ediciones Trilce.

Díaz Suasa, Dora Isabel (2002). Situación de la mujer rural colombiana. Perspectiva de género. Cuadernos Tierra y Justicia, (9), 4-8.

Díaz, María Camila (2015). Salteadores y cuadrillas de malhechores. Una aproximación a la acción colectiva de la "población negra" en el suroccidente de la Nueva Granada 1840-1851. Popayán: Universidad del Cauca.

Duby, Georges y Perrot, Michelle (2000). El siglo Xx: los grandes cambios del siglo y la nueva mujer. Madrid: Editorial Taurus. 
Escobar, Arturo (2008). Territorios de diferencia, lugar, movimientos, vidas, redes. Bogotá: Envión Editores.

Fanon, Frantz (1973). Piel negra, máscaras blancas. Buenos Aires: Editorial Abraxas.

Flórez, Juliana (2004). Imposición identitaria y movimientos sociales: desafíos y logros del proceso de comunidades negras ante las relaciones de género. Conflicto e invisibilidad. En Restrepo, E., Retos de los estudios de la gente negra en Colombia, pp. 219-246, Popayán: Editorial Universidad del Cauca.

Gargallo, Francesca (2014). Feminismos desde el Abya Yala. Ideas y proposiciones de las mujeres de 607 pueblos en nuestra América. Ciudad de México: Editorial Corte y Confección.

Guber, Rosana (2001). La etnografía, método, campo y reflexividad. Bogotá: Editorial Norma.

Hill, Patricia (2012). Rasgos distintivos del pensamiento feminista negro. En Jabardo M., Feminismos Negros, una antología, pp. 101-131, Madrid: Traficantes de Sueños.

Hurtado Saa, Teodora (2001). La protesta social en el norte del Cauca y el surgimiento de la movilización étnica colombiana. En Pardo Mauricio. Acción colectiva, Estado y etnicidad en el Pacífico colombiano, pp. 95-122, Bogotá: Instituto Nacional de Antropología e Historia.

Ibarra Melo, María Eugenia (2007). Acciones colectivas de las mujeres en contra de la guerra y por la paz en Colombia. Revista Sociedad y Economía, (13), 66-86.

Jabardo Velasco, Mercedes (2012). Construyendo puentes: en diálogo desde/ con el feminismo negro. En Jabardo M., Feminismos Negros, pp. 101-131, Madrid: Traficantes de Sueños.

Jaramillo Sierra, Isabel Cristina (2003). Instrucciones para salir del discurso de los derechos. En La crítica de los derechos, pp. 11-19, Bogotá: Siglo del Hombre Editores.

Keck, Margaret y Sikkink, Kathryn (1998). Activistas sin fronteras. México D. F.: Siglo XXI. 
Lagarde de los Ríos, Marcela (2006). Pacto entre mujeres sororidad. Aportes para el Debate, (13), pp. 123-135. Recuperado de https://www.asociacionag.org.ar/pdfaportes/25/09.pdf.

Lamus Canavete, Doris (2010). De la subversión a la inclusión: movimientos de mujeres de la segunda ola en Colombia, 1975-2005. Bogotá: Instituto Colombiano de Antropología e Historia.

Lamus Canavete, Doris (2012). El color negro de la (sin) razón blanca: el lugar de las mujeres afrodescendientes en los procesos organizativos en Colombia. Colombia: Universidad Autónoma de Bucaramanga.

Lamus Canavete, Doris (2015). Guía para la investigación cualitativa y de género. Colombia: Doris Lamus Cavañete.

Lorde, Audré (2002). La hermana, la extranjera. Madrid: Horas y Horas.

Marcus, Georges (2001). Etnografía en/del sistema mundo. El surgimiento de la etnografía multilocal. Alteridades, (11), pp. 111-127.

Mina Rojas, Charo; Rojas Silva, Jeannette; Estupiñán Valencia, Danelly y Casiani, Teresa (2012). Informe derrotar la invisibilidad. un reto para las mujeres afrocolombianas en Colombia. Proyecto Mujeres Afrocolombianas Defensoras de Derechos Humanos. Proceso de Comunidades Negras (PCN).

Montero, Justa (2006). Feminismo: un movimiento crítico. Intervención Psicosocial, (15), pp.167-180.

Montoya Arango, Vladimir y García Sánchez, Andrés (2010) ¡Los afro somos una diversidad! Identidades, representaciones y territorialidades entre jóvenes afrodescendientes de Medellín, Colombia. Boletín de Antropología Universidad de Antioquia, (24), pp. 44-64.

Muñoz Cabrera, Patricia (2011). Violencias interseccionales. Debates feministas y marcos teóricos en el tema de pobreza y violencia contra las mujeres en Latinoamérica. Tegucigalpa: Central America Women’s Network (CAWN).

Pardo, Mauricio (2001). Estado y movimiento negro en el Pacífico colombiano. En Acción colectiva, estado y etnicidad en el Pacífico colombiano. pp. 229258, Bogotá: Instituto Colombiano de Antropología e Historia. 
Restrepo, Eduardo (2004). Biopolítica y alteridad: dilemas de la etnización de las Colombias negras. En Conflicto e invisibilidad. Retos de los estudios de la gente negra en Colombia. Popayán: Universidad del Cauca.

Sánchez Muñoz, Cristina (2008). Genealogía de la vindicación negra. En Feminismos debates teóricos contemporáneos. Madrid: Alianza Editorial.

Sánchez, Cristina; Beltrán, Elena y Álvarez, Silvina (2008). Feminismo liberal, radical y socialista. En Feminismos debates críticos contemporáneos. Madrid: Alianza Editorial.

Santamaría Chavarro, Ángela del Pilar (2012). Eclosiones identitarias. Interseccionalidad y feminismo(s) en jaque. En Identidades políticas porosas. Estudio sobre las reivindicaciones sociales nacionales y transnacionales, movilización legal, discursos políticos y reportorios de acción de las organizaciones indígenas y la lucha contra el racismo en Colombia. Bogotá: Editorial Universidad del Rosario.

Segato, Rita Laura (2003). El género en la antropología y más allá de ella. Las estructuras elementales de la violencia. Ensayos sobre género entre la antropología, el psicoanálisis y los derechos humanos. Buenos Aires: Universidad Nacional de Quilmes.

Segato, Rita Laura (2011). Género y colonialidad: en busca de claves de lectura y de un vocabulario estratégico descolonial. En Karina Bidaseca y Vanesa Vázquez Laba, Feminismos y Poscolonialidad. Descolonizando el feminismo desde y en América Latina. Buenos Aires: Ediciones Godot.

Sánchez Gómez, Olga Amparo (1995). El movimiento social de mujeres. La construcción de nuevos sujetos sociales. En Las mujeres en la historia de Colombia, (1). Bogotá: Editorial Norma.

Valcárcel, Amelia (2001). La memoria colectiva y los retos del feminismo. Serie Mujer y Desarrollo, (32), pp. 5-33. Recuperado de file:///D:/Downloads/ memoria-retos-feminismo.pdf.

Varela, Nuria (2008). Feminismo para principiantes. Barcelona: Ediciones B.

Viveros, Mara (2000). Dionisios negros. Estereotipos sexuales y orden racial en Colombia. En iMestizo yo? Diferencia, identidad e inconsciente. Jornadas sobre Mestizaje y Cultura en Colombia. Bogotá: Universidad Nacional de Colombia. 
Viveros, Mara (2016). La interseccionalidad: una aproximación situada a la dominación. Debate Feminista, (52). Recuperado de https://bit.ly/2TzxaXg

Viáfara López, Carlos (2013). Informe de la situación de Derechos Humanos de las mujeres afrocolombianas. Bogotá: Agencia Española de Cooperación Internacional para el Desarrollo (Aecid). Mesa Nacional de Organizaciones Afrocolombianas.

Wabgou, Maguemati; Arocha Rodríguez, Jaime; Salgado Cassiani, Alden Jóse y Carabalí Ospina, Juan Alberto (2012). Movimiento social, afrocolombiano, negro, raizal y palenquero: el camino hacia la construcción de espacios comunes y alianzas estratégicas para la incidencia política en Colombia. Bogotá: Universidad Nacional de Colombia.

Williams, Patricia (2003). La dolorosa prisión del lenguaje de los derechos. En La crítica de los derechos. Bogotá: Siglo del Hombre Editores. 